\title{
Filtros solares e fotoprotetores - uma revisão
}

\author{
Sunscreens and photoprotection compounds - a review
}

\author{
Lorena Dias da Silva CABRAL, Samara de Oliveira \\ PEREIRA, Anette Kelsei PARTATA* \\ FAHESA / ITPAC-Instituto Tocantinense Presidente Antônio Carlos, \\ Rua Buenos Aires, 1002. Setor Martim Jorge. Araguaina (TO). CEP: 77817530. \\ Brasil.E-mail: anettepartata@hotmail.com
}

\begin{abstract}
Excessive exposure to the sun without protection represents a major risk for the development of malignant tumors. Substances for protecting the skin, such as sunscreens has the attention of the market. The development of effective and safe sunscreen, is obtained through knowledge of their mechanisms of action and formulations. Sunscreens, besides protect against ultraviolet radiation, can hydrate and rejuvenate the skin. We are presenting a literature review about sunscreens and the phenomena involving photo protection, submit ratings, mechanism of action and the assessment methods of sun protection, and finally highlight the importance of using of sunscreen in preventing photoaging and skin cancer. It is noteworthy that the use of combinations of filters as organic with inorganic compounds can increase the spectrum of protection, allowing higher FPS with reduced cost and power irritant reactions. The combination of zinc oxide with titanium dioxide allows the obtention of formulations with low irritant and allergenic potential and they may be used by sensitive individuals. These combinations represent the advancement of technology and possibilities for new products to market safely.
\end{abstract}

KEYWORDS: chemical sunscreens, physical sunscreens; Photoprotection; Photoaging.

\section{RESUMO}

A exposição excessiva ao sol e sem proteção representa um dos maiores riscos para o desenvolvimento de tumores malignos. $\mathrm{O}$ uso de substâncias para proteger a pele, como os filtros solares, tem a atenção do mercado. $\mathrm{O}$ desenvolvimento de fotoprotetores com eficácia e segurança é obtido através do conhecimento de seus mecanismos de ação e formulações. Os filtros solares e fotoprotetores, além de proteger contra os raios ultravioletas, podem hidratar e rejuvenescer a pele. O estudo é uma revisão bibliográfica sobre filtros solares e fotoprotetores, com objetivos de revisar os fenômenos que envolvem os filtros solares, apresentar as classificações, o mecanismo de ação e os métodos de avaliação da proteção solar, e por fim, evidenciar a importância do uso do filtro solar na prevenção do fotoenvelhecimento e do câncer de pele. Ressalta-se que o uso de combinações como de filtros inorgânicos com orgânicos aumentam o espectro de proteção, permitindo maior FPS com redução do custo e a potência de reações irritantes. A associação de óxido de zinco com dióxido de titânio permite obter formulações com baixo potencial alergênico e irritante, podendo ser utilizada por indivíduos mais sensíveis. Estas combinações representam o avanço da tecnologia e possibilidades para novos produtos no mercado com segurança.

PALAVRAS CHAVE: Filtros solares químicos; Filtros solares físicos; Fotoproteção; Fotoenvelhecimento.

\section{LISTA DE ABREVIAÇÕES:}

$\mathrm{A} / \mathrm{O}$ - água/óleo

$\mathrm{O} / \mathrm{A}$ - óleo/água

FPS - Fator de proteção solar

PABA - ácido para-aminobenzóico

PVP - polivinil pirrolidona

UVA - radiação ultravioleta A

UVB - radiação ultravioleta $B$

\section{INTRODUÇÃO}

O Brasil está localizado com grande parte de sua superfície demográfica entre o trópico de Capricórnio e o Equador. Por isso é uma região que recebe a maior intensidade de radiações solares, o que torna o país de maior área intertropical. É nesta área que existe um aumento do número de pessoas com câncer de pele. 
O fotoenvelhecimento consiste no exagero das alterações cutâneas resultantes da exposição solar. É denotado como causa de rugas, manchas, aspereza, telangiectasias e cor amarela na pele. A prevenção é o tratamento mais eficaz, sendo importante principalmente para as pessoas de pele clara.

Além da ação direta dos raios solares na pele, existe, também, a ação exercida pela difusão e reflexão. $\mathrm{O}$ cuidado em se proteger com chapéu ou guarda-sol não protege a pele contra a ação difundida ou refletida dos raios. A radiação ultravioleta também atravessa vidros e é importante proteger-se, e conhecendo os mecanismos de ação e formulação dos filtros solares é possível verificar sua eficácia e segurança.

O estudo é uma revisão bibliográfica sobre filtros solares e fotoprotetores, com objetivos de revisar os fenômenos que envolvem os filtros solares, apresentar as classificações, o mecanismo de ação e os métodos de avaliação da proteção solar, e por fim, evidenciar a importância do uso do filtro solar na prevenção do fotoenvelhecimento e do câncer de pele.

\section{EFEITOS BIOQUÍMICOS DE RADIAÇÃO SOLAR NA PELE}

Os efeitos bioquímicos da radiação solar sobre a pele são causados, principalmente, pelas radiações UVA e UVB (1).

A radiação UVA bronzeia por ser mais penetrante, atinge a derme profunda, tornando-se o principal responsável pelo fotoenvelhecimento, fotossensibilização e o aparecimento de rugas e flacidez. A radiação UVB, apesar da penetração através da pele ser menor, pode chegar até a derme papilar e com isto provocar alterações às fibras de elastina e de colágeno. Portanto, os raios UVB também participam do processo de fotoenvelhecimento, são mais nocivos, provocam a formação de queimadura, câncer de pele e catarata; e além disso, atingem a epiderme, provocando a sensação de ardência, vermelhidão e queimaduras (2).

\section{CLASSIFICAÇÃO DOS FILTROS SOLARES}

\section{Filtros Solares Físicos ou Inorgânicos}

Filtros solares físicos ou inorgânicos são aqueles que funcionam como barreira (3). Os principais representantes dessa classe de produto são: dióxido de titânio e óxido de zinco. Menos importantes, pode-se citar ainda: o talco, o carbonato de cálcio, o caolin, o óxido de ferro, o petrolato vermelho etc (4).

Estas substâncias possuem baixo potencial alergênico, podendo ser especialmente importante para formulações de produtos infantis, para uso diário e para indivíduos com peles sensíveis (5).
Agentes físicos são impermeáveis à radiação, refletindo-a em sua maior parte (6). Na reflexão/dispersão, a luz incidente nas partículas inorgânicas é redirecionada, refletindo de volta ou se espalhando por diferentes caminhos. Este processo é responsável pela translucidez e opacidade das partículas de filtros inorgânicos aplicadas sobre a pele (7).

O dióxido de titânio e o óxido de zinco exibem grande absorção semicondutora de radiação UV e refletem e espalham a radiação na região do visível e UV. Por isso, são considerados os filtros físicos mais eficientes, justificando o emprego destas substâncias com maior frequência nas preparações solares (8).

O dióxido de titânio é capaz de absorver o UVB, mas não o UVA, e dependendo do tamanho da partícula deste filtro inorgânico, é refletido. Por outro lado, o óxido de zinco tem a capacidade de absorver a radiação UV em toda sua extensão (7).

\section{Filtros Solares Químicos}

Filtros solares químicos absorvem $95 \%$ da radiação UV nos comprimentos de onda de 290 a 320nm. Esse é o espectro UV, conhecido como a variação da queimadura solar desde que esses comprimentos de onda de energia de luz produzem eritema de pele e enrugamento (7).

Os filtros químicos são classificados em: ácido para-aminobenzóico (PABA) e derivados; salicilatos; benzimidazóis; derivados do benzilideno cânfora e benzofenas (6).

A estrutura dos filtros orgânicos permite que absorvam os raios UV nocivos ao ser humano, ou seja, radiação com alta energia, convertendo-a numa radiação inócua com baixa energia. A energia UV absorvida por uma molécula é liberada quando esta retorna ao seu estado de repouso. Todavia, a liberação da mesma se dá na forma de luz fluorescente ou fosforescente e calor, podendo, ainda, se decompor e formar fotoprodutos. Portanto, um filtro solar absorve energia prejudicial e a transforma em formas de energia não agressivas para pele (5).

\section{Filtros solares naturais}

São derivados de óleos vegetais, extratos glicólicos ou fluídos que absorvem a radiação UVA/UVB. Têm absorção considerada baixa. Como a fotoestabilidade do produto ainda não é totalmente conhecida, é necessário ter cautela quanto à sua utilização. $\mathrm{O}$ recomendado é utilizá-los como coadjuvantes aos filtros químicos físicos. Extratos glicólicos dos seguintes ingredientes têm ação de proteção solar: alecrim, amor-perfeito, babosa, camomila, café-verde, algodão, amendoim, côco e gergelim (1).

\section{COMBINAÇÃO DE FILTRO SOLARES}

A associação dos filtros inorgânicos dióxido de 
titânio e óxido de zinco permite obter formulações finais com baixo potencial alergênico e irritante, o que é especialmente importante para formulações de produtos infantis, para uso diário, para indivíduos com peles sensíveis e área dos olhos. Além desta vantagem, conseguem-se produtos com amplo espectro de ação utilizando-se apenas filtros inorgânicos, uma vez que o dióxido de titânio atenua, principalmente, a radiação UVB, enquanto o óxido de zinco atenua a radiação UVA (6).

\section{FORMULAÇÕES RESISTENTES OU MUITO RESISTENTES À ÁGUA E SUOR}

A presença na formulação de substâncias hidrofóbicas e ou hidrorrepelentes é fundamental para esta ação. Um filtro solar pode ser classificado como resistente à água e como muito resistente à água. Os ingredientes hidrorrepelentes devem ser preferencialmente citados no rótulo, uma vez que o fato de ser resistente ou à prova d'água não elimina a necessidade da reaplicação, embora esta possa ser realizada em intervalos maiores (9).

Para conseguir resistência à água ou suor devem ser adicionados às formulações agentes filmógenos que fixam os filtros na pele, impedindo sua retirada ao entrarem em contato com a água. Os formadores de filme que conferem resistência à água são os copolímeros de polivinil pirrolidona (PVP) eicosano, hexadeceno e tricotanil (5).

\section{DETERMINAÇÃO DO FATOR DE PROTEÇÃO SOLAR (FPS)}

Após o desenvolvimento de uma formulação de filtro solar faz-se necessário a determinação do FPS, uma vez que seu valor deve constar no rótulo, conforme normas da resolução $\mathrm{n}^{\circ}$ 237, de 22 de agosto de 2002 (5).

O FPS mede o grau de proteção na pele que um produto oferece contra os raios UVB, indicando quanto tempo uma pessoa pode ficar exposta ao sol usando um cosmético protetor solar sem formar eritema $(8,10)$.

\section{PROPRIEDADES DOS PRINCÍPIOS ATIVOS ASSOCIADOS AOS FOTOPROTETORES}

Se um indivíduo pode ficar ao sol por 10 minutos sem nenhuma proteção, com filtro de FPS 15 este tempo irá se prolongar 15 vezes, isto é, 150 minutos (2 horas e 30 minutos). Vale ressaltar que os filtros solares devem ser reaplicados em intervalos de 3-4 horas (1).

Os princípios ativos que podem ser associados aos filtros solares devem ser estáveis à luz e ao calor; não podem variar de cor, não devem manchar a roupa e muito menos a pele. Devem, ainda, manter a sua eficácia por períodos prolongados, ser solúveis em solventes não-comedogênicos e ter boa fixação na pele, mesmo após banho de mar e piscina, esportes e suor. Os silico- nes contribuem significativamente para este fim. Outros ativos comuns em formulações fotoprotetoras: sais de ácidos carboxílicos, aminoácidos e derivados, ureia, antioxidantes (vitamina $\mathrm{E}$, vitamina $\mathrm{C}$, beta-caroteno, superóxido dismutase), helioxina, fotossomas, nitreto de boro $(1,7)$.

\section{VEÍCULOS E EXCIPIENTES UTILIZADOS NOS FOTOPROTETORES}

Os mais utilizados são: os não-iônicos, emulsões água/óleo (A/O) ou óleo/água (O/A) e os géis não-iôni$\cos$, que dão sensação lubrificante sobre a pele; e o carbômero, iônico, que possui toque seco. As emulsões A/O ou $\mathrm{O} / \mathrm{A}$ ajudam, inclusive, a diminuir a agressão do sol na pele, pois possuem agentes emolientes e hidratantes na formulação $(9,11)$.

Os óleos, suspensões e, sobretudo, os cremes, são mais aderentes, especialmente os últimos, se forem muito gordurosos, sendo, portanto, menos facilmente removíveis pela água; têm, porém, o inconveniente de darem brilho à pele, sujarem a roupa, prenderem areia e poeira e serem, por vezes, de difícil remoção (4).

\section{ACONSELHAMENTO FARMACÊUTICO AO USUÁRIO DE FOTOPROTETORES}

Os filtros solares são classificados como cosméticos de acordo com a RDC n 47 de 16 de março de 2006. Mesmo não sendo um medicamento, o filtro solar deve ter uso adequado por inúmeros fatores, devendo ser considerados tanto aqueles relacionados ao paciente que busca proteção, quanto àqueles relacionados à própria formulação $(7,12)$.

Abaixo estão algumas informações que o farmacêutico pode repassar ao paciente no ato do aconselhamento farmacêutico, que o orientará a se proteger e como este deverá agir para evitar os possíveis danos como o fotoenvelhecimento e o câncer de pele:

- Aplicar o fotoprotetor 20 a 30 minutos antes de se expor ao sol. Esse é o tempo necessário para se formar um filme protetor homogêneo, que produza o efeito desejado (13).

- O filtro solar deve ser repassado a cada 2 ou 3 horas, de modo especial se a exposição for mais permanente. Depois, na hora da retirada, é importante que se lave bem o corpo, retirando os resíduos químicos (3).

- Pessoas que se expõem diariamente ao sol devem fazê-lo pela manhã cedo. Deve-se evitar o sol entre 10 horas e 16 horas (9).

- Mesmo em dias nublados, cerca de $80 \%$ dos raios UV atravessam as nuvens e a neblina (2).

- Sempre utilizar filtros solares que protejam tanto do UVA como UVB (7). 


\section{CONCLUSÕES}

Os filtros solares e os fotoprotetores são classificados conforme o tipo de proteção que oferecem bloqueio físico ou absorção química da radiação UV. Assim, pode-se definir os fotoprotetores como agentes que atenuam o efeito carcinogênico por mecanismo de absorção, reflexão ou dispersão da radiação e, possivelmente, prevenção do fotoenvelhecimento da pele exposta. São considerados fenômenos físicos, desde que não ocorra reação química durante os processos de absorção e reflexão de radiação.

O fotoenvelhecimento sobrepõe-se ao envelhecimento intrínseco e ocorre em áreas expostas sem pro- teção ao sol. A radiação UV é um acelerador do envelhecimento cutâneo e o fotodano é cumulativo ao longo de toda a vida de um indivíduo, pois danos causados na adolescência se acumulam e se manifestam no futuro. No entanto, pouco se discute e pouco se propaga em relação à necessidade da aplicação devidamente correta do filtro solar sobre a pele, tanto do ponto de vista qualitativo como quantitativo.

\section{AGRADECIMENTOS}

FAHESA / ITPAC - Instituto Tocantinense Presidente Antônio Carlos.

9. Ferreira AO; Silva MADCG. Protetores Solares. In: Ferreira AO. Guia Prático da Farmácia Magistral. 3.ed. São Paulo: Pharmabooks, 2008. Cap.12, p.273-303.

10. Mendonça VLM; Kedor ERM. Proteção Solar x Fator de Proteção. Revista Racine 34:14, 1996.

11. Souza VM. Controle do Sistema Pigmentar. In: Ativos dermatológicos: Guia de ativos dermatológicos utilizados na farmácia de manipulação, para médicos e farmacêuticos. São Paulo: Tecnopress, 2010. p.77-80.

12. Souza VM. Fotoprotetores. In: Ativos dermatológicos: Um guia dos novos ativos dermatológicos utilizados na farmácia de manipulação, para médicos e farmacêuticos. São Paulo: Tecnopress, 2011. p.39-62.

13. Draelos ZD. Fotoenvelhecimento, Filtros Solares e Cosmecêuticos. In: Cosméticos em Dermatologia. 2.ed. Rio de Janeiro: Revinter, 1999. Cap.23, p.245-256

Cosmetologia Aplicada a Dermoestética. São Paulo: Pharmabooks, 2006. p.77-120.

8. Salgado C; Galante MC; Leonardi GR. Filtros solares: Mecanismos de ação e metodologias em preparações magistrais. Int $\mathrm{J}$ Pharm Compounding. 6(4):.224-236, 2011. 